\title{
Genomic heterogeneity in synchronous hepatocellular carcinomas
}

Y Sirivatanauksorn, V Sirivatanauksorn, S Bhattacharya, B R Davidson, A P Dhillon, A K Kakkar, R C N Williamson, N R Lemoine

\begin{abstract}
Background-Hepatocellular carcinoma (HCC) arising in cirrhosis is frequently multifocal. Whether HCC develops monoclonally or multiclonally is an unresolved question. Of the multiple tumour nodules present in many patients, it has not been established whether the smaller lesions represent intrahepatic metastases or de novo cancers.
\end{abstract}

Aims-To assess the degree of genomic heterogeneity in synchronous HCCs in cirrhosis.

Methods-The arbitrarily primed polymerase chain reaction technique was utilised to compare the DNA fingerprint of HCCs and regenerative nodules (RNs) removed from cirrhotic explant livers.

Department of Surgery, Royal Free and University College Medical School, Royal Free Hospital, London, UK

Y Sirivatanauksorn

S Bhattacharya

B R Davidson

University

Department of

Histopathology, Royal

Free and University

College Medical

School, Royal Free

Hospital, London, UK

A P Dhillon

Department of

Gastrointestinal

Surgery, Imperial

College School of

Medicine,

Hammersmith

Hospital, London, UK

A K Kakkar

R C N Williamson

Imperial Cancer Research Fund

Molecular Oncology

Unit, Imperial College

School of Medicine,

Hammersmith

Hospital, London, UK

V Sirivatanauksorn

N R Lemoine

Correspondence to: Professor N R Lemoine, Imperial Cancer Research Fund Molecular Oncology Unit, Imperial College

School of Medicine,

Hammersmith Hospital,

Du Cane Road, London

W12 ONN, UK.

Accepted for publication 2 June 1999 of patients presenting with surgically resectable tumours remains low at $10-15 \%$ of the total patient population with primary HCC worldwide. Recurrence is commonly observed in the cirrhotic liver, rates of up to $80 \%$ being reported within five years of resection. ${ }^{3}$ Screening of cirrhotic patients for the detection of small HCCs may improve prognosis of this disease. ${ }^{4}$ However, even if suspected lesions are detected and biopsied, small HCCs are still difficult to diagnose morphologically by conventional pathological methods, especially when they are less than $1.5 \mathrm{~cm}$ diameter. In the setting of cirrhosis, there are no agreed criteria for the diagnosis of these tumours. The smallest HCCs begin as well differentiated tumours, which generally dedifferentiate and become heterogeneous as they grow above $1.5 \mathrm{~cm} .{ }^{5}$ Our inability to identify them at this size is likely to limit the effectiveness of treatment.

Whether HCC in human liver develops from a single clone or from multiple parallel clones is an unresolved question. Information on the clonal origin of tumours will influence management strategies for prevention of recurrence after operation. Various techniques have been developed to assess the clonality in tumours, such as the detection of alterations in oncogenes or tumour suppressor genes, ${ }^{67}$ integration of HBV into the cellular genome, ${ }^{89} \mathrm{X}$ linked restriction fragment length polymorphisms within the tumour, ${ }^{10}$ analysis of DNA ploidy pattern, ${ }^{11}$ and the demonstration of a specific cytogenetic abnormality. However, only a small fraction of HCC exhibit point mutations of specific oncogenes or tumour suppressor genes, and integrated HBV DNA can only be used as a marker in those patients who have viral infection. $\mathrm{X}$ linked restriction fragment length polymorphisms are limited to tumours in women, while the analysis of DNA content does not detect the cell with a balanced gain or loss of chromosomes, or with genetic rearrangements.

Recently the arbitrarily primed polymerase chain reaction (AP-PCR) method was developed as a technique which generates an information rich and unbiased fingerprint of genomic DNA without requiring prior knowledge of nucleotide sequence information. ${ }^{12}$ It is based on the selective amplification of genomic sequences that, by chance, are flanked by adequate matches to an arbitrarily chosen primer. This method utilises amplification with a single arbitrary primer and it has been applied to detect and isolate DNA fragments of somatic genomic changes that show losses or gains in cancer. ${ }^{13}$ Moreover, it is a highly specific technique that is able to generate species specific and individual diagnostic DNA
Abbreviations used in this paper: AP-PCR, arbitrarily primed polymerase chain reaction; $\mathrm{HBV}$, hepatitis B virus; HCC, hepatocellular carcinoma; $\mathrm{MRN}$, macroregenerative nodule; $\mathrm{RN}$, regenerative nodule. 
fingerprints. ${ }^{14}$ Of the multiple tumour nodules present in many patients, it has not been established whether the smaller lesions represent intrahepatic metastases or de novo cancers. We therefore assessed the degree of genomic heterogeneity in synchronous HCCs using AP-PCR. If two template genomic DNA sequences are different, their arbitrarily primed PCR products display different fingerprinting patterns.

\section{Materials and methods}

TISSUE SAMPLES

Tissue samples used in this study were cirrhotic explant livers from patients undergoing elective orthotopic liver transplantation for end stage chronic liver disease at the Royal Free Hospital. The formalin fixed livers were cut into coronal slices $10 \mathrm{~mm}$ thick and closely examined for unusual nodules. If any unusual

A

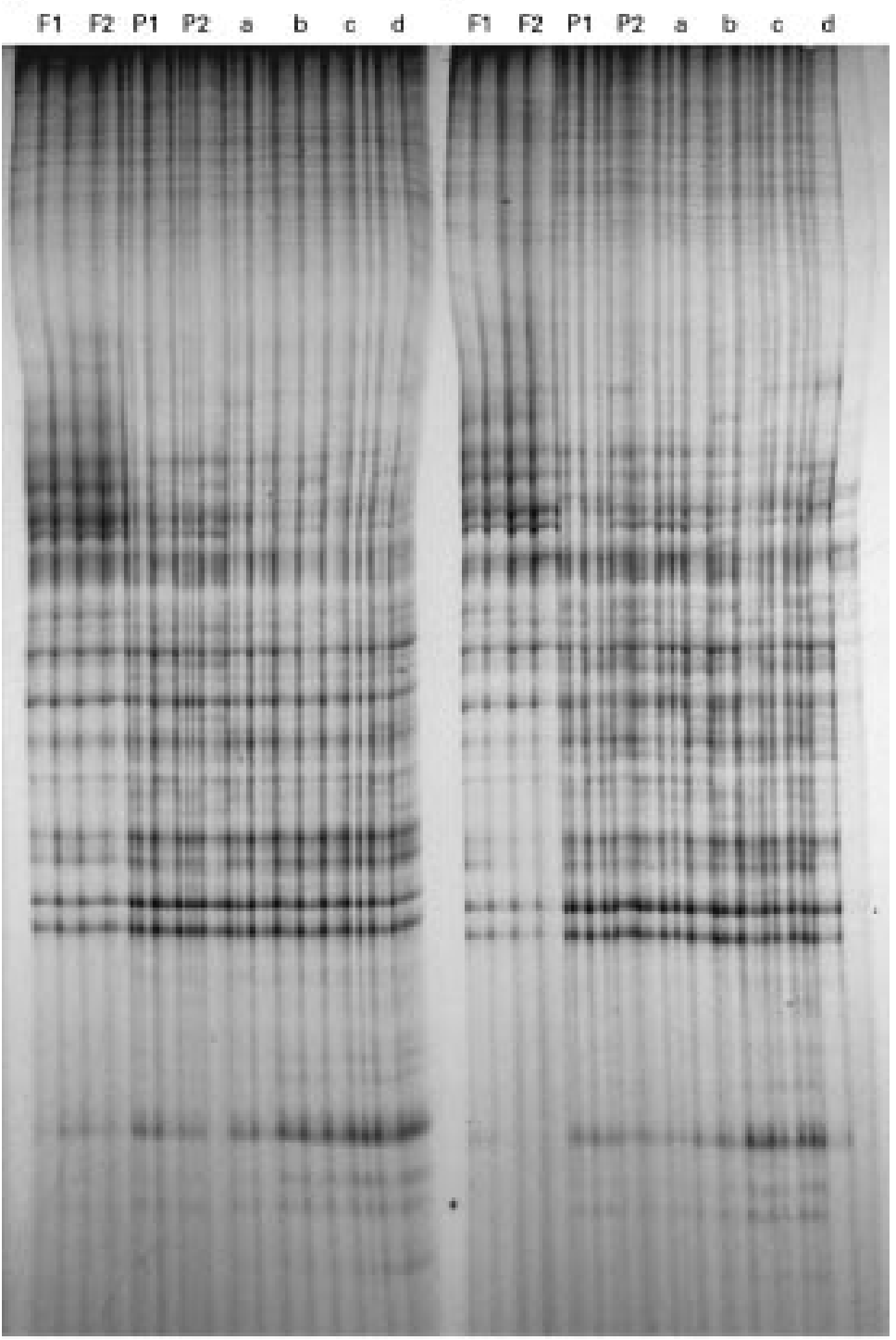

Figure 1 AP-PCR fingerprint patterns of fresh frozen and formalin fixed, paraffin wax embedded blocks of two segments ( $A$ and $B$ ) of non-cirrhotic liver from a single patient. Identical profiles were observed on amplification of DNA from microdissected samples at different levels of the frozen blocks (F1 and F2) and paraffin wax blocks (P1 and P2).

Similar results were obtained on amplification of various concentrations (a: $50 \mathrm{ng} ; \mathrm{b}: 100 \mathrm{ng}$; c: $200 \mathrm{ng} ; \mathrm{d}: 400 \mathrm{ng}$ ) of template DNA from each of the paraffin wax blocks. nodules were found, tissue samples were taken from these nodules, embedded in paraffin wax, and processed using standard techniques. The details of nodule selection and pathological categorisation have been described previously. ${ }^{15}$

One $5 \mu \mathrm{m}$ section and ten $10 \mu \mathrm{m}$ sections were serially cut from each archival block onto glass slides by microtome. The first $5 \mu \mathrm{m}$ section was stained with haematoxylin and eosin (H\&E) for histological confirmation. Normal gallbladder tissues from each patient were used to generate the fingerprint pattern of their normal constitutional DNA for comparison.

MICRODISSECTION AND DNA PREPARATION

The remaining $10 \mu \mathrm{m}$ sections were stained with $0.1 \%$ toluidine blue solution for 10 minutes. Tissue samples were separately prepared by microdissection using sterile 27 gauge needles with the assistance of a dissection microscope, and referenced to a section stained with H\&E. Deparaffinisation was achieved by incubating in xylene by 20 minutes at $55^{\circ} \mathrm{C}$ and then washing twice with absolute ethanol. DNA was prepared by incubating tissue in lysis buffer $(10 \mathrm{mM}$ Tris. $\mathrm{Cl} \mathrm{pH} 8.0,50 \mathrm{mM} \mathrm{KCl}$, $2.5 \mathrm{mM} \mathrm{MgCl}, 0.1 \mathrm{mg} / \mathrm{ml}$ gelatin, $0.45 \%$ NP-40, $0.45 \%$ Tween 20, proteinase K 500 $\mu \mathrm{g} / \mathrm{ml}$ ) overnight at $55^{\circ} \mathrm{C}$. The lysate was subjected to three phenol/chloroform/isoamyl alcohol (25:24:1, by volume) extractions. After ethanol precipitating, washing, and drying the DNA, it was resuspended in sterile water and the concentration was determined by spectrophotometry.

OPTIMISATION AND VALIDATION OF AP-PCR ON PARAFFIN WAX EMBEDDED MATERIAL

We investigated the parameters that affected the production of reproducible AP-PCR fingerprints. The number, reproducibility, and intensity of bands in a fingerprint should be a function of several parameters, therefore various concentrations of template (50-400 ng), $\mathrm{Mg}^{2+}$ (1.5-7.5 mM), $\mathrm{K}^{+}$(250-1000 $\mathrm{mM}$ ), and $\mathrm{pH}(7.5-10.0)$ have been investigated. To compare the effect of tissue fixation and processing, normal non-cirrhotic liver tissue was divided into two pieces; the first was snap frozen in liquid nitrogen, while the other was fixed in formalin, embedded in paraffin wax, and processed using standard techniques. A 5 $\mu \mathrm{m}$ section was serially cut from each block onto glass slides and stained with H\&E. Tissues from both slides were microdissected from different depths through the block (to test the effects of different lengths of exposure to formalin fixation) and separately collected in microfuge tubes. DNA extraction was performed as above.

AP-PCR

Two different arbitrarily primers (AR3 ${ }^{16}: 5^{\prime}-$ GCGAATTCATGTACGTCAGG-3'; ZF ${ }^{17}$ : 5'-CCCCACCGGAGAGAAACC-3') were utilised to amplify the genomic DNA of each sample. Five $\mu \mathrm{mol}$ of an arbitrary primer were labelled with $\gamma-{ }^{33} \mathrm{P}$ (Amersham, UK) using T4 polynucleotide kinase (Bioline, UK) at $37^{\circ} \mathrm{C}$ 
A

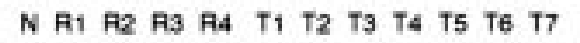

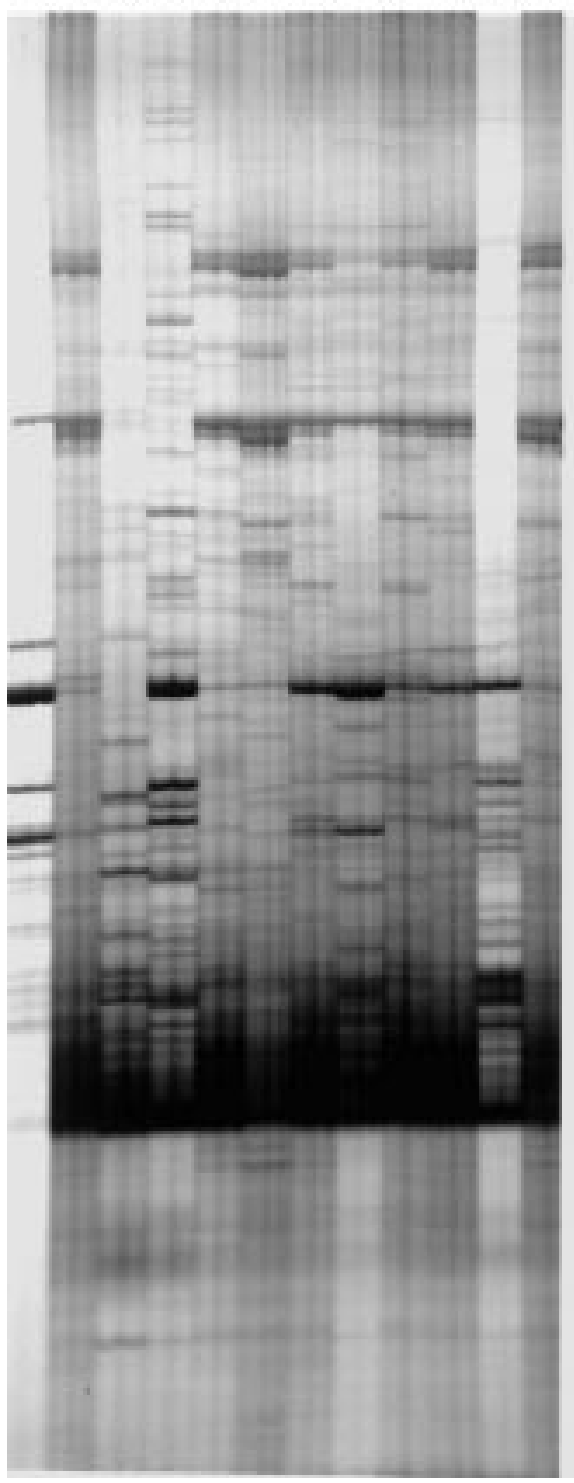

for one hour. AP-PCR amplifications were carried out using $200 \mathrm{ng}$ template DNA in a reaction mixture containing $5 \mu \mathrm{M}$ of ${ }^{33} \mathrm{P}$ labelled arbitrary primer, $0.2 \mathrm{mM}$ each dNTP (Bioline, UK), $10 \mathrm{mM}$ Tris. $\mathrm{Cl} \mathrm{pH} \mathrm{9.2,} 3.5 \mathrm{mM}$ $\mathrm{MgCl}_{2}, 75 \mathrm{mM} \mathrm{KCl}$, and 0.5 units of Taq DNA polymerase (Bioline, UK) in a final volume of $25 \mu \mathrm{l}$. The reactions were overlaid with mineral oil and cycled through the following temperature profile: $94^{\circ} \mathrm{C}$ for one minute to denature, $45^{\circ} \mathrm{C}$ for five minutes for low stringency annealing of primer, and $72^{\circ} \mathrm{C}$ for five minutes for extension for four cycles. This temperature profile was followed by high stringency cycles: $94^{\circ} \mathrm{C}$ for one minute, $60^{\circ} \mathrm{C}$ for one minute, and $72^{\circ} \mathrm{C}$ for two minutes for 35 cycles, with a final extension at $72^{\circ} \mathrm{C}$ for 10 minutes. To ensure reproducibility, all amplifications were performed in duplicate on each sample with a Hybaid Thermoreactor (Hybaid). The PCR product was added to $5 \mu \mathrm{l}$ of dye mixture and subsequently run on $8 \%$ polyacrylamide gel electrophoresis in a Model S2 Sequencing Gel

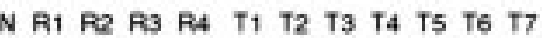

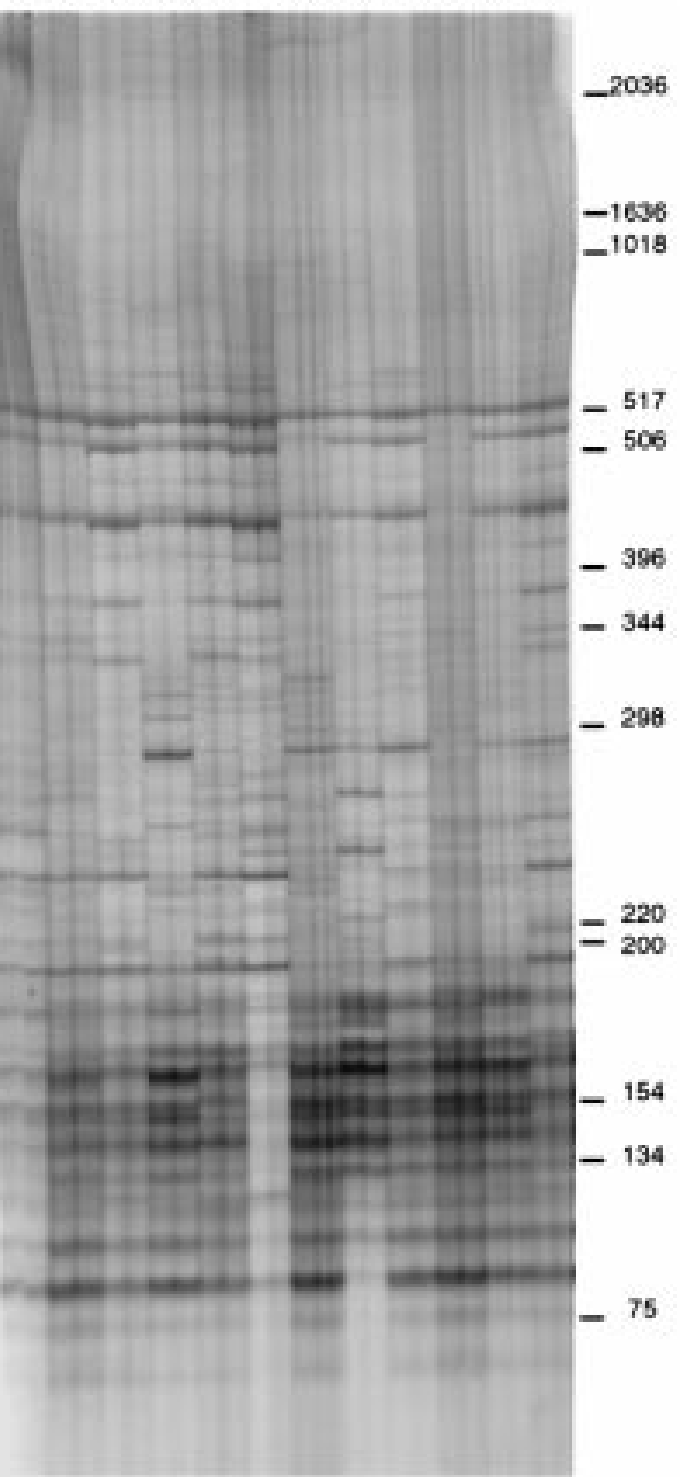

Electrophoresis Apparatus (GibcoBRL Life Technologies, UK). After electrophoresis, the gel was transferred to a piece of Whatman $3 \mathrm{MM}$ paper, dried using a gel dryer (Flowgen, $\mathrm{UK}$ ), and exposed to $x$ ray film (BioMax MR, Kodak, USA) for 24-48 hours at room temperature.

\section{Results}

When run on a polyacrylamide gel, the fingerprint patterns generated by AP-PCR from a particular template with either the AR3 or ZF3 primer were consistent over a wide range of template concentrations. Moreover, they were consistent for $\mathrm{Mg}^{2+}, \mathrm{K}^{+}$, and $\mathrm{pH}$ at 3.5-7.5 $\mathrm{mM}, 750-1000 \mathrm{mM}$, and 7.5-9.2 respectively (data not shown). We found identical fingerprinting patterns in AP-PCR reactions of DNA extracted from paired frozen and formalin fixed tissues from an individual sample (fig 1). Similar results were observed in the tissues dissected from different depths. 
A

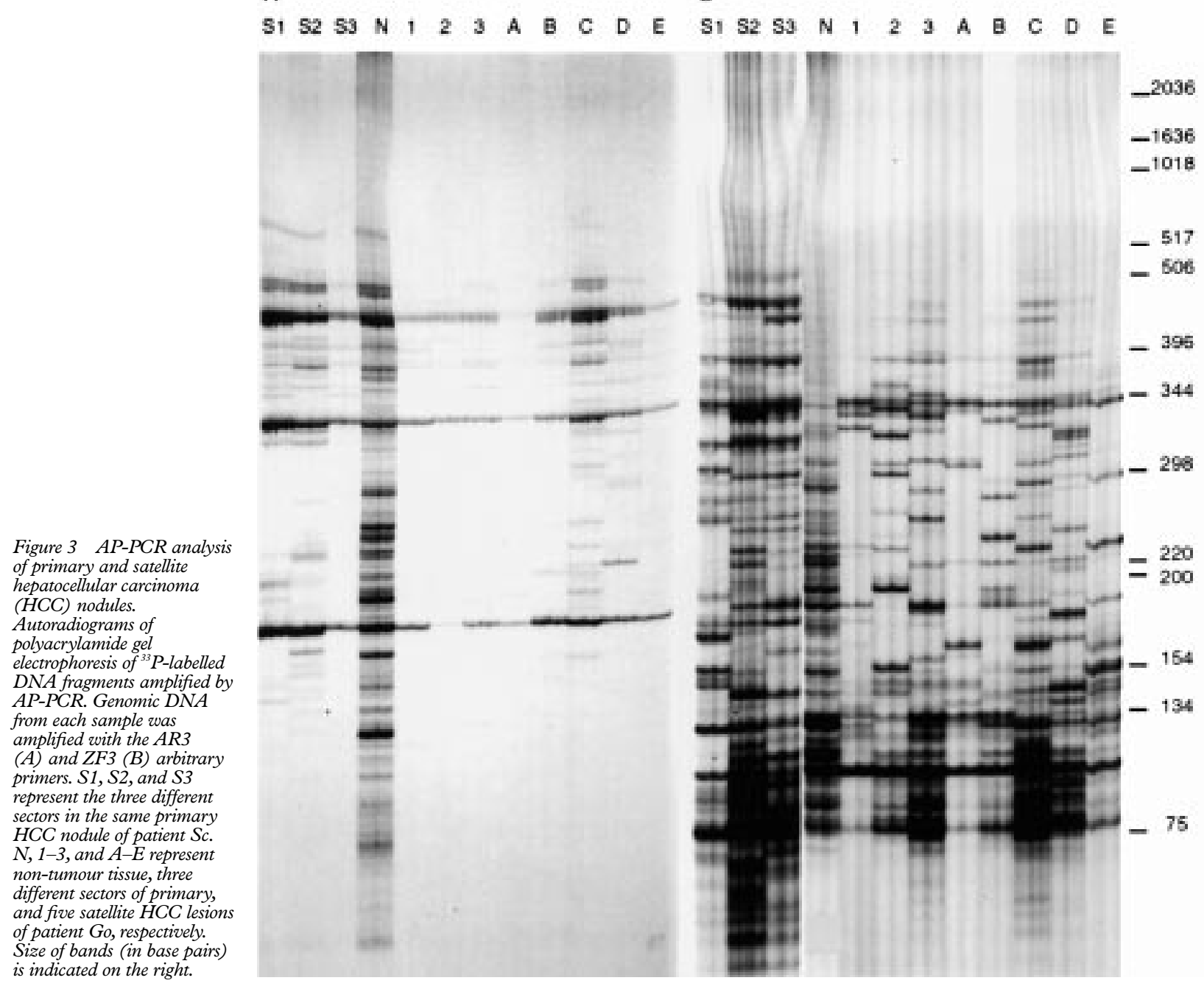

Fifty four HCCs, 31 regenerative nodules (RNs), adjacent benign cirrhotic nodules from 13 cirrhotic explant livers removed at orthotopic liver transplantation, and normal gallbladder tissues were microdissected from the sections of each sample. The mean size of the HCCs was 7.69 (5.56) $\mathrm{mm}$ and of the RNs 7.87 (3.39) $\mathrm{mm}$ in diameter.

Using AP-PCR with each of the two arbitrary primers, we generated specific and reproducible DNA fingerprints, which were highly polymorphic between different nodules. Each PCR reaction was performed in duplicate with equal aliquots of sample template DNA, and the fingerprint of these paired reactions was identical, confirming the reproducibility of the technique. Genomic homogeneity was detected in the two different sectors (whether closely adjacent or widely separated) of normal tissues of each patient, confirming the specificity of the technique. Nevertheless, DNA fingerprinting of RNs and HCCs was different from that of normal gallbladder tissue in the same patient. Notable genomic heterogeneity was recorded among the nodules studied (fig 2). No two nodules (either RNs or HCCs) had identical electrophoretic patterns. Contrary to expectation, even "satellite" nodules in close proximity within the same segment of the liver were found to have distinct genomic patterns (fig 3).

\section{Discussion}

AP-PCR is a highly specific technique that is able to generate species specific and individual diagnostic DNA fingerprints. ${ }^{14}$ The low stringency of the early cycles ensures the generation of products by allowing priming with mismatches between primers and many sequences in the total genomic DNA. The subsequent PCR cycles are performed at a higher stringency after the generation of some initial products that now have ends complementary to the primers. Competition between the annealing events during the initial low stringency cycles results in the reproducible and quantitative amplification of many discrete bands during the subsequent high stringency cycles. Different template genomic DNA sequences display electrophoretic banding patterns in their AP-PCR fingerprints with a number of differences that is inversely proportional to the extent of similarity of the two genomes. This technique has not been previously used to assess the genomic relation between synchronous HCC nodules. We found that AP-PCR is a simple and effective approach 
for analysing the genetic profile in multiple HCC nodules. Polymorphisms in genomic fingerprints generated by AP-PCR can distinguish between each nodule. Moreover, we successfully showed reproducible and interpretable fingerprinting patterns of amplified genomic DNA isolated from paraffin wax embedded tissues.

The determination of clonality of human tumours has important implications for the mechanisms of carcinogenesis. Resected liver specimens sometimes show small nodular lesions without definite features of cancer in addition to the main HCC. Unfortunately, these lesions are not clearly defined, nor is their nomenclature established. They have been variously referred to as adenomatous hyperplasia, nodular hyperplasia, adenomatous hyperplastic nodules, and macroregenerative nodules (MRNs). In view of such a confused definition of these nodules, we used the term regenerative/macroregenerative nodules (RNs/ MRNs) according to the proposals of Ferrell et $a l .^{18}$ Previous studies showed that the presence of MRNs was significantly associated with an increased incidence of liver cell dysplasia and HCC compared with cirrhotic livers without MRNs. ${ }^{1920}$ It has been suggested that MRNs are possible precancerous lesions. Our findings showed a distinctly different molecular profile among all RNs examined, whereas previous reports of the incidence of monoclonal RNs (based on HBV or HCV analysis) varied from $0.5 \%$ to $43 \% .^{21-23}$ In this study, the DNA fingerprints of RNs were different from those of HCCs, even in the same patient, which suggests that HCC may develop independently of $\mathrm{RN}$, by bypassing a rather persistent stage of precancerous nodules. Favouring this view, a previous study showed that no MRNs in 17 patients without treatment developed into HCC in 13-51 months of follow up; indeed, the nodules disappeared in four cases. However, HCCs developed apart from the MRNs in four of these patients during this period. ${ }^{24}$ There is also an experimental model of de novo occurrence of HCCs in animal models without any precancerous nodular formation. ${ }^{25}$

Although most HCCs were once believed to be monoclonal in origin, ${ }^{52}$ recent studies have shown that a certain proportion of HCCs clearly involve multiclonal development. ${ }^{82126}$ A recent study also showed heterogeneity of DNA content in multiple synchronous HCCs. ${ }^{27}$ With the background of an anomalous hepatic parenchyma, multiple HCCs can arise independently from different foci in the liver. The genetic heterogeneity in synchronous HCCs may be the result of (in)activation of specific gene loci in the neoplasm, as alternative consequences to the continued presence of carcinogen. Such genomic heterogeneity in synchronous HCCs may explain their poor response to treatment. The high recurrence rate is still a major problem after curative resection of HCC, even for small tumours. If the smaller tumours are de novo lesions rather than metastases (as these data suggest), current concepts regarding liver resection as a curative treatment modality for HCC may require reassessment.

However, this information is based on the explant livers from patients with cirrhosis. Whether the same phenomenon is present in HCCs at an earlier stage of liver disease has not been established. The advent of novel techniques for laser microdissection of single cells may facilitate such analysis. ${ }^{28}$

1 Wands JR, Blum HE. Primary hepatocellular carcinoma. $N$ Engl f Med 1991;325:729-31.

2 Okuda K. Hepatocellular carcinoma: recent progress. Hepatology 1992;15:948-63.

3 Chen MF, Hwang TL, Jeng LB, et al. Postoperative recurrence of hepatocellular carcinoma. Two hundred and five consecutive patients who underwent hepatic resection five consecutive patients who underwent

in 15 years. Arch Surg 1994;129:738-42.
4 Oka H, Kurioka N, Kim K, et al. Prospective study of early Oka $\mathrm{H}$, Kurioka $\mathrm{N}$, Kim K, et al. Prospective study of early detection of hepatocellular carcino
cirrhosis. Hepatology 1990;12:680-7.

5 Kondo F, Wada K, Nagato Y, et al. Biopsy diagnosis of welldifferentiated hepatocellular carcinoma based on new morphologic criteria. Hepatology 1989;9:751-5.

6 Tada M, Omata M, Ohto M. Analysis of ras gene mutations in human hepatic malignant tumors by polymerase chain reaction and direct sequencing. Cancer Res 1990;50:1121-4.

7 Hsu IC, Metcalf RA, Sun T, et al. Mutational hotspot in the p53 gene in human hepatocellular carcinomas. Nature 1991;350:427-8.

8 Sakamoto M, Hirohashi S, Tsuda H, et al. Multicentric independent development of hepatocellular carcinoma revealed by analysis of hepatitis B virus integration pattern. Am $\mathcal{F}$ Surg Pathol 1989;13:1064-106.

9 Hsu HC, Chiou TJ, Chen JY, et al. Clonality and clonal evoHsu HC, Chiou TJ, Chen JY, et al. Clonality and clonal evo-
lution of hepatocellular carcinoma with multiple nodules. lution of hepatocellular carcin
Hepatology 1991;13:923-8.

10 Vogelstein B, Fearon ER, Hamilton SR, et al. Use of restriction fragment length polymorphisms to determine the clonal origin of human tumors. Science 1985;227:642-5.

11 Nagasue N, Kohno H, Chang YC, et al. DNA ploidy pattern in synchronous hepatocellular carcinomas. $\mathcal{F}$ Hepatol 1992; 16:208-14.

12 Welsh J, McClelland M. Fingerprinting genomes using PCR with arbitrary primers. Nucleic Acids Res 1990;18:7213-18.

13 Peinado MA, Malkhosyan S, Velazquez A, et al. Isolation and characterization of alllelic losses and gains in colorectal tumors by arbitrarily primed polymerase chain reaction. Proc Natl Acad Sci USA 1992;89:10065-9.

14 Schlegel J, Vogt T, Munkel K, et al. DNA fingerprinting of mammalian cell lines using nonradioactive arbitrarily
primed PCR (AP-PCR). BioTechniques 1996;20:178-80.

15 Bhattacharya S, Dhillon AP, Rees J, et al. Small hepatocellular carcinomas in cirrhotic explant livers: identification by macroscopic examination and lipiodol localization. Hepamacroscopic examinati
tology 1997;25:613-18.

16 Achille A, Biasi MO, Zamboni G, et al. Chromosome 7q allelic losses in pancreatic carcinoma. Cancer Res 1996;56: 3808-13

17 Welsh J, McClelland M. Genomic fingerprints produced by PCR with consensus tRNA gene primers. Nucleic Acids Res 1991;19:861-6.

18 Ferrell LD, Crawford JM, Dhillon AP, et al. Proposal for standardized criteria for the diagnosis of benign, borderline, and malignant hepatocellular lesions arising in chronic advanced liver disease. Am f Surg Pathol 1993;17:1113-23.

19 Furuya $K$, Nakamura M, Yamamoto Y, et al. Macroregenerative nodule of the liver. A clinicopathologic study of 345 105 .

20 Hytiroglou P, Theise ND, Schwartz M, et al. Macroregenerative nodules in a series of adult cirrhotic liver explants: issues of classification and nomenclature. Hepatology 1995; issues of c1:703-8.

21 Aoki N, Robinson WS. State of hepatitis B viral genomes in cirrhotic and hepatocellular carcinoma nodules. Mol Biol Med 1989;6:395-408.

22 Yasui H, Hino O, Ohtake K, et al. Clonal growth of hepatitis $\mathrm{B}$ virus-integrated hepatocytes in cirrhotic liver nodules. Cancer Res 1992;52:6810-14

23 Aihara T, Noguchi S, Sasaki Y, et al. Clonal analysis of regenerative nodules in hepatitis $\mathrm{C}$ virus-induced liver cirrhosis. Gastroenterology 1994;107:1805-11.

24 Kondo F, Ebara M, Sugiura N, et al. Histological features and clinical course of large regenerative nodules: evaluation of their precancerous potentiality. Hepatology 1990;12:592-8.

25 Kohen H, Pugh TD, Goldfarb S. Hepatocarcinogenesis in the mouse: combined morphologic-stereologic studies. $\mathrm{Am}$ the mouse: combined morpho $1983 ; 112: 89-110$.

26 Sheu JC, Huang GT, Chou HC, et al. Multiple hepatocellular carcinomas at the early stage have different clonality. Gastroenterology 1993;105:1471-6.

27 Hui AM, Kawasaki S, Imamura $\mathrm{H}$, et al. Heterogeneity of DNA content in multiple synchronous hepatocellular carcinomas. Br $\mathcal{F}$ Cancer 1997;76:335-9.

28 Emmert-Buck MR, Bonner RF, Smith PD, et al. Laser capture microdissection. Science 1996;274:998-1001. 